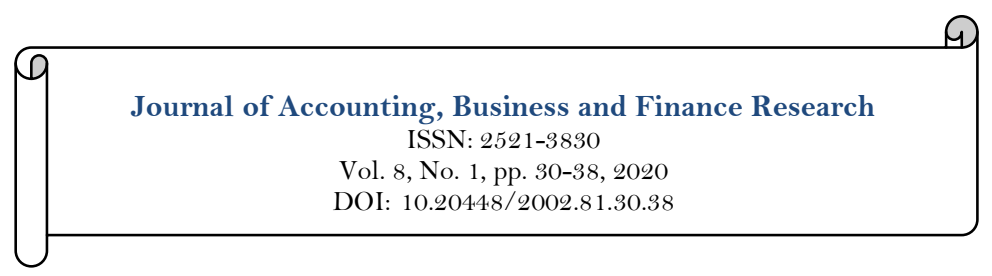

\title{
Intellectual Property Rights Protection, Foreign Technology Introduction and FDI- Based on the Provincial-Level Panel Data of China
}

\author{
Jingchao Dai \\ PhD Candidate, School of Economics, Central University of Finance and Economics, Beijing, China. \\ Email:jingchaodai2017@163.com
}

\begin{abstract}
This article establishes static and dynamic panel models of 30 provinces in China, using a variety of regression models and regression methods to empirically study the impact of China's intellectual property rights (IPR) protection on FDI. Then verifying whether the impact of intellectual property rights protection on FDI is subject to the level of foreign technology introduction. The innovativeness is constructing a quantitative index system of intellectual property protection of China, which includes intellectual property rights protection legislative level and intellectual property rights protection enforcement level. The research results show that the level of legislation and enforcement of intellectual property rights protection have significant positive impact on China's FDI. For some provinces which urgently need to introduce advanced foreign technology, strengthening intellectual property rights protection will inhibit FDI. Especially the strengthening of the intellectual property rights protection legislative level has a more pronounced inhibitory effect.
\end{abstract}

Keywords:

Intellectual property rights

$F D I$

Foreign technology introduction

China.

JEL Classification: O30;F4. .

Licensed:

This work is licensed under a

Creative Commons Attribution 4.0

License.

Publisher:

Scientific Publishing Institute

Accepted: 6 December 2019 Published: 30 December 2019

Funding: The study did not have any funding support.

Competing Interests: The author declares that there are no conflicts of interests regarding the publication of this paper.

\section{Introduction}

The intellectual property protection system is an important property right system and legal system, which can effectively protect and stimulate the enthusiasm of knowledge creation and technical innovation of the whole society. At present, accelerating the pace of establishing and improving the intellectual property protection system, as well as stepping up the pace of international intellectual property arrangement have become important national strategies and the main focus for each country to enhance its comprehensive national strength, promote economic development and promote technological progress. As China has been entered the era of knowledge economy, intellectual property protection is playing an important role on attracting foreign investment, introducing advanced technology, researching and innovating independently, and promoting international trade. After TRIPS, economists began to focus on in-depth research about the optimal level of protection of intellectual property rights and other issues. One of the research hotspots is how the level of intellectual property protection affect foreign direct investment (FDI).

For developing countries, increasing foreign direct investment can promote a country's technological innovation and economic growth. Whether the country establishes and improves the protection of intellectual property, and how thoroughly and to what extend the strength of intellectual property protection system is, have already become important considerations for foreign investment. On the one hand, intellectual property is a kind of property right. If a country fails to protect intellectual property effectively, it will form an 
intangible investment barrier and affect the willingness of the foreign company to invest directly. Therefore, strengthening and improving the intellectual property protection system will attract FDI. At the same time, it can be said that to meet the requirements of the global distribution of intellectual property rights made by developed countries and multinational companies, developing countries should strengthen the emphasis on intellectual property protection, the level of legislation and the enforcement of law, as well as bring them in line with the international level of intellectual property protection. This is also necessary moves to integrate into the track of market. On the other hand, there is a gap of the scientific and technological level between the developing countries and the developed countries. The accumulation of knowledge in developing countries are in the initial stage. Their stock of knowledge are also relatively weak. Therefore, the introduction of foreign advanced technology can be a way to imitate and thus enhance developing countries' research and innovation capability. So if developing countries make strict laws and policies of intellectual property protection, which is not accommodated and not in accordance with their actual situation, it will increase the cost of the introduction of technology, impede knowledge dissemination, and affect the speed of knowledge accumulation, eventually leading to economic slowdown and then inhibiting foreign investment. That means it will reduce FDI inflows if strengthen and improve the IPR protection. Therefore, the academic circles have not reached a unified answer on the direction and extent of the impact of the level of intellectual property protection on a country's FDI.

Through establishing static panel and dynamic panel models of China's provincial-level data from 2001 to 2016, and constructing quantitative indicators of intelligent property right protection level which includes legislation level and enforcement level, this article empirically studies the impact of China IPR protection level on FDI inflows, and then further verifies whether the impact is restricted to foreign technology introduction level. The structure of this article is as follows: the second part is a literature review on the relationship between intellectual property right protection and FDI; the third part is model setting, variable interpretation, data description, data source and data description; the fourth part is empirical analysis on the impact of intellectual property protection and foreign technology introduction on FDI; the five part is the conclusion and policy implications.

\section{Literature Review}

Nordhaus (1969) studied the intellectual property protection system with the patent protection system and found that the initial implementation of the intellectual property protection system would hinder the free competition in the market, but its long-term impact was to stimulate innovation and creativity; Nordhaus also put forward the basic balance theory, which is the theoretical basis of establishment and improvement of optimal patent system or optimal intellectual property rights protection system. A lot of academic research literature has emerged at home and abroad on whether the establishment and improvement of intellectual property protection systems in various countries accord with the basic balance theory and how to promote technological progress and economic growth by establishing the optimal intellectual property protection system. For example, scholars have investigated the correlation between intellectual property protection system and economic growth, FDI, export trade, TFP, independent R\&D, financial development and other fields, or established a quantitative index system to measure the level of intellectual property protection, or to study the relationship between the strong intellectual property protection system or the weak intellectual property protection system and the economic development level of the economically developed countries or the economically underdeveloped countries, and put forward the design problem of the inverted u-shaped intellectual property system.

There are many domestic and foreign studies on the impact of intellectual property protection on a country's FDI inflow, but the research conclusions are not uniform. Maskus and Penubarti (1995) found that when the level of intellectual property protection in a country was relatively weak at the initial stage, further strengthening of intellectual property protection would have the opposite effect, that is, reducing the amount of FDI inflows. Maskus (1998) found that the higher the level of intellectual property protection in developing countries is, the more the US invests in them, that is, the more attractive it is to the US. Carsten, Braga, and Carlos (2001) found that there was no exact correlation between the amount of FDI inflows and the degree of intellectual property protection in the country, which was different from the research conclusions of the above scholars. Yang and Ying (2006) found that if a country can implement a reasonable and efficient intellectual property protection system, it can increase the inflow of FDI, promote the introduction of advanced technology, promote the economic growth of the country, and further promote the welfare maximization of the host country. Yu and Wang (2009) found that the impact of intellectual property protection level on FDI inflow is uncertain. Strengthening intellectual property protection can increase FDI inflow, but too strict intellectual property protection system will reduce FDI inflow

At present, few literatures distinguish the level of intellectual property protection into the level of legislation and enforcement, and then verify the impact of legislative level and enforcement level on China's FDI inflow respectively and examine how these effects interact with the level of foreign technology imports. Therefore, this paper constructs an index system to measure the legislative level and law enforcement level of intellectual property protection in each provincial administrative region, establishes static panel model and 
dynamic panel model to solve the above problems, and uses a variety of models or methods for regression analysis and result verification

\section{Model Setup and Data Description}

\subsection{Econometric Model Setting and Variable Explanation}

This paper selects data of 30 provincial level administrative regions in China from 2001 to 2016. Through regression analysis, this paper finds out the correlation between intellectual property protection legislation level and enforcement level of intellectual property protection and FDI, estimates the impact of China's current intellectual property protection level on FDI. Reference to the relevant literature on intellectual property protection, in this paper, the basic model, panel model $\mathrm{A}$ is set as:

$$
\begin{aligned}
\ln \left(F D I_{i, t}\right)= & \beta_{0}+\beta_{1} I P L_{i, t-1}+\beta_{2} I P E_{i, t}+\beta_{3} \ln \left(F T I_{i, t}\right)+\beta_{4} \ln \left(O P E N_{i, t}\right)+\beta_{5} \ln \left(R \& D_{i, t}\right) \\
& +\beta_{6} \ln \left(F I_{i, t}\right)+\beta_{7} \mu_{i}+\varepsilon_{i, t}
\end{aligned}
$$

Where i stands for Chinese province, $t$ stands for year. Since China joined the WTO in 2001, there are new requirements for China's intellectual property protection system, which need to be integrated into the international environment to meet international requirements. Therefore, the data selected in this paper starts from 2001.

$F D I_{i_{s}}$ represents the level of FDI of province i in year t,IPL $L_{i_{3} t-1}$ represents the legislative level of

intellectual property protection of province i in year t-1,IPE $E_{i, t}$ represents the enforcement level of intellectual

property protection of province $\mathrm{i}$ in year $\mathrm{t}$. The higher the level of legislation and law enforcement on intellectual property protection in a provincial-level administrative region, the better it can protect the intellectual property generated in the process of foreign investment. Therefore, the more it can attract foreign investment, the more FDI inflow. However, if considering the level of foreign technology introduction, strong intellectual property protection system will inhibit imitated innovation and technological progress, which is not conducive to local economic growth, thus reducing the willingness of foreign direct investment.

In this paper, four control variables are added into the regression model:FTI $i_{i, t}$ represents the foreign

technology import level of province $\mathrm{i}$ in year t; $O P E N_{i, t}$ represents the opening level of province $\mathrm{i}$ in year

$\mathrm{t} ; R \& D_{i, t}$ represents the level of $\mathrm{R} \& \mathrm{D}$ of province i in year $\mathrm{t} ; F I_{i, t}$ represents the fixed asset investment level of

province $\mathrm{i}$ in year $\mathrm{t}$. The more foreign technologies are introduced, the more advanced technologies can be applied and learned by each provincial administrative region, which is more conducive to economic development and thus attracts more attention and further investment from foreign investors. The higher the degree of opening to the outside world, the smaller the trade friction and trade cost of the region, means the more opportunities for foreign investment, and the more conducive to attracting foreign investors. The higher the level of technology research and development, the stronger the capability of independent research and development, means the higher the market competitiveness, the higher the rate of return on investment, and the greater the attraction to foreign direct investment. The higher the level of fixed assets investment means the better the local economic development investment foundation, the more attraction to foreign investment. In addition, $\mu_{i}$ stands for individual effect; $\varepsilon_{i, t}$ represents the residual following a standard normal distribution.

Panel model A is a basic regression model to study the impact of intellectual property protection level on FDI. In order to further study the interaction between the level of intellectual property protection and the level of foreign technology import on FDI, this paper also sets the panel model B, which includes the interaction between the level of intellectual property protection legislation as well as the level of intellectual property protection law enforcement and the level of foreign technology import.

$$
\begin{aligned}
\ln \left(F D I_{i, t}\right)=\beta_{0} & +\beta_{1} I P L_{i, t-1}+\beta_{2} I P E_{i, t}+\beta_{3} \ln \left(F T I_{i, t}\right)+\beta_{4} \ln \left(O P E N_{i, t}\right)+\beta_{5} \ln \left(R \& D_{i, t}\right) \\
& +\beta_{6} \ln \left(F I_{i, t}\right)+\beta_{7} I P L_{i, t-1} * \ln \left(F T I_{i, t}\right)+\beta_{8} I P E_{i, t} * \ln \left(F T I_{i, t}\right)+\beta_{9} \mu_{i}+\varepsilon_{i, t}
\end{aligned}
$$

Considering the continuity of FDI, this paper adds the first-order lag of FDI to the panel model A, and constructs the dynamic panel model $\mathrm{C}$ to estimate the dynamic changes of explained variables. 


$$
\begin{gathered}
\ln \left(F D I_{i, t}\right)=\beta_{0}+\rho \ln \left(F D I_{i, t-1}\right)+\beta_{1} I P L_{i, t-1}+\beta_{2} I P E_{i, t}+\beta_{3} \ln \left(F T I_{i, t}\right)+\beta_{4} \ln \left(O P E N_{i, t}\right) \\
+\beta_{5} \ln \left(R \& D_{i, t}\right)+\beta_{6} \ln \left(F I_{i, t}\right)+\beta_{7} \mu_{i}+\varepsilon_{i, t}
\end{gathered}
$$

\subsection{Data Source and Data Description}

FDI uses the total amount of FDI invested by foreign-invested enterprises and takes its logarithm to eliminate heteroscedasticity. The data come from China Statistical Yearbook. To measure the level of intellectual property protection, the intellectual property protection index established by Ginarte and Park (1997) namely the GP index, is mainly used internationally. In China, the measurement method of Han and Li (2005) or the improved index of intellectual property protection based on them (Xu \& Shan, 2008) are mainly used. Based on the construction method of intellectual property protection indicators proposed by Shi and Gu (2013); Li and Chen (2017) this paper sets the intellectual property protection legislation level index and the intellectual property protection law enforcement level index, which are defined as follows:

$\mathrm{IPL}=\quad\left(0.7^{*}\right.$ Cumulative number of infringement disputes filed in province $\mathrm{i}+$

$0.3^{*}$ Cumulative number of counterfeit patent cases filed in province i)/

Cumulative number of patent applications authorized in province $\mathrm{i}$

$\mathrm{IPE}=$ (Cumulative number of infringement disputes settled in province i/

Cumulative number of infringement disputes filed in province $\mathrm{i})^{*}$

$\ln$ (Cumulative number of patent applications authorized in province i)

The larger IPL means more patent infringement disputes and counterfeit patent acts have laws to be filed, which is compared with the number of patents authorized in each provincial administrative region. That also means the higher the level of legislation for intellectual property protection. The larger IPE means the stricter handling of IPR infringement disputes after be filed, and the improvement of law enforcement level will further encourage patent applications and accelerate the speed of patent applications. Due to the endogenous problem of intellectual property protection legislation, the IPL is subject to a one-stage lag value. Data related IPL and IPE are from China Statistical Yearbook, Patent Statistical Annual Report and CSMAR.

The data of foreign technology import level (FTI) is foreign technology import contract amount, which is from China Science and Technology Database, and taken with its logarithm value. The level of opening to the outside world (OPEN) is represented by the total volume of import and export in the place where the business unit is located and its logarithm value is taken. The data are from China Statistical Yearbook. The data of R\&D level (R\&D) uses internal expenditure of research and experimental development (R\&D) funds, and take its logarithm value. The data are from the China Science and Technology Database. For fixed asset investment level (FI), using per capita fixed asset investment of the whole society, and taking its logarithm value. The data are from China Statistical Yearbook. The descriptive statistics of variables in this paper are shown in Table 1.

Table-1. Descriptive statistics of variables.

\begin{tabular}{c|c|c|c|c|c}
\hline Variable & Mean & Std.Dev & Min & Max & Obs \\
\hline lnfdi & 7.723287 & 1.471224 & 3.769362 & 11.07754 & $\mathrm{~N}=480$ \\
\hline ipe & 7.320038 & 1.609294 & 3.095285 & 12.09604 & $\mathrm{~N}=480$ \\
\hline L.ipl & 8.957261 & 8.741533 & 0.790561 & 82.0871 & $\mathrm{~N}=450$ \\
\hline lnfti & 2.469768 & 1.960954 & -4.11197 & 6.632063 & $\mathrm{~N}=479$ \\
\hline lnopen & 7.272116 & 1.724881 & 2.789685 & 11.12142 & $\mathrm{~N}=480$ \\
\hline lnrd & 13.60153 & 1.587848 & 9.042749 & 16.82866 & $\mathrm{~N}=480$ \\
\hline lnfi & 9.462123 & 0.996889 & 7.257658 & 11.317 & $\mathrm{~N}=480$ \\
\hline
\end{tabular}

\section{Empirical Analysis}

This paper constructs an index system to measure the level of intellectual property protection in provincial administrative regions, namely the intellectual property protection legislation index (IPL) and the intellectual property protection enforcement index (IPE).The 16 years panel regression model of 30 provincial administrative regions is constructed to incorporate the individual situation of each provincial region into the model. Moreover, three-dimensional data covering period sections and variables are used to make up the shortage of the model's short time range, so as to make the empirical analysis of the actual economic situation more comprehensive, rigorous and true.

\subsection{Regression Analysis of the Static Panel Model-the Basic Model}

In this paper, the panel model A is regressed using the methods of Pooled-OLS Model, Fixed Effect Model and Random Effect Model, and all the regression results are based on the cluster-robust standard error. This paper also uses the F Test, LM Test, Hausman Test and Robust Hausman Test to verify the model setting. The regression results of Pooled-OLS Model, FE Model and RE Model are shown in Table 2. 
Table-2. Regression results of panel model A (basic model).

\begin{tabular}{|c|c|c|c|c|c|}
\hline & (1) & $(2)$ & (3) & $(4)$ & $(5)$ \\
\hline LnFDI & Pooled-OLS & FE_within & FE_LSDV & RE_FGLS & RE_MLE \\
\hline \multirow[t]{2}{*}{ ipe } & 0.0424 & $0.0909^{* * * *}$ & $0.0909^{* * *}$ & $0.0986^{\text {**** }}$ & $0.0966^{* * * *}$ \\
\hline & $(0.0823)$ & $(0.0319)$ & $(0.0330)$ & $(0.0364)$ & $(0.0240)$ \\
\hline \multirow[t]{2}{*}{ L.ipl } & -0.00818 & $0.00734^{* *}$ & $0.00734^{* * *}$ & 0.00477 & $0.00553^{* *}$ \\
\hline & $(0.0111)$ & $(0.0034)$ & $(0.0035)$ & $(0.0037)$ & $(0.0027)$ \\
\hline \multirow[t]{2}{*}{ lnfti } & $0.107^{\text {***** }}$ & 0.0126 & 0.0126 & 0.0231 & 0.0196 \\
\hline & (0.0339) & $(0.0180)$ & $(0.0186)$ & $(0.0160)$ & $(0.0153)$ \\
\hline \multirow[t]{2}{*}{ lnopen } & $0.560^{* * * *}$ & $0.203^{\text {****** }}$ & $0.203^{* * * *}$ & $0.342^{\text {***** }}$ & $0.302^{* * * *}$ \\
\hline & $(0.1190)$ & $(0.0693)$ & $(0.0717)$ & $(0.0612)$ & $(0.0495)$ \\
\hline \multirow[t]{2}{*}{$\ln r d$} & 0.0797 & 0.193 & 0.193 & $0.247^{* * * *}$ & $0.238^{* * * *}$ \\
\hline & $(0.1510)$ & $(0.1290)$ & $(0.1340)$ & $(0.0928)$ & $(0.0552)$ \\
\hline \multirow[t]{2}{*}{$\operatorname{lnfi}$} & 0.0485 & $0.212^{*}$ & 0.212 & 0.0558 & $0.0948^{*}$ \\
\hline & $(0.0655)$ & $(0.1220)$ & (0.1260) & $(0.0737)$ & $(0.0514)$ \\
\hline \multirow[t]{2}{*}{ _cons } & $1.602^{*}$ & 0.855 & 0.751 & 0.533 & $0.593^{*}$ \\
\hline & $(0.8490)$ & $(0.6910)$ & $(0.7660)$ & $(0.5390)$ & $(0.3130)$ \\
\hline$R^{2}$ & 0.878 & 0.799 & 0.966 & & \\
\hline
\end{tabular}

Column (1) in Table 2 shows the results of regression using Pooled-OLS Model. The results show that the regression coefficient of intellectual property legislation level is negative, which is inconsistent with the expectation of this paper. The coefficient of intellectual property law enforcement level is positive, which is consistent with the expectation of this paper, indicating that the stronger the enforcement of intellectual property rights is, the more China's FDI growth will be promoted. But neither is significant.

Columns (2) and (3) in Table 2 are the results of regression using the Fixed Effects Model, where column (2) uses the Within Estimation method, and column (3) uses the LSDV method. The results show that the regression coefficient of intellectual property legislation level is 0.0074 , and the significance level is $5 \%$.Regression coefficient of IPR enforcement level is 0.09, and the significance level is $1 \%$ ( Within Estimation method ) and 5\%(LSDV method). The regression coefficient of intellectual property legislation level and intellectual property law enforcement level is both positive and significant, which is in line with the expectation of this paper, indicating that the greater the degree of intellectual property legislation and law enforcement, the more China's FDI growth will be promoted. The regression results of other control variables in the model are all in line with the expectation of this paper, but the coefficient of foreign technology introduction and R\&D is not significant.

Column (4) and column (5) in Table 2 are the results of regression using the Random Effects Model, where column (4) uses the FGLS method, and column (5) uses the MLE method. The results show that the regression coefficient of intellectual property legislation level using FGLS method is 0.0048, but not significant. The coefficient of intellectual property law enforcement level using FGLS method is 0.0986, and the significance level is $1 \%$. The regression coefficient of intellectual property legislation level using MLE method is 0.0055 , with the significance level of $5 \%$. The regression coefficient of intellectual property law enforcement level using MLE method is 0.0966, and its significance level is $1 \%$. The regression coefficient of intellectual property legislation level and intellectual property law enforcement level is both positive and significant, which is in line with the expectation of this paper, indicating that the greater the degree of intellectual property legislation and law enforcement, the more China's FDI growth will be promoted. The regression results of other control variables in the model are in line with the expectation of this paper, but the coefficient of foreign technology introduction is not significant

In Table 2 different regression methods are used to obtain different results for panel model A. Therefore, F Test, LM Test, Hausman Test and Robust Hausman Test are used to verify the model setting, as shown in Table 3 .

Table-3. Test of panel model A(basic model) setting.

\begin{tabular}{l|l|l|l}
\hline \multirow{2}{*}{ F test } & F-value & P-value & Model selection \\
\cline { 2 - 4 } & 37.06 & O & Reject Pooled-OLS \\
\hline \multirow{4}{*}{ LM test } & $\boldsymbol{X}^{2}$ & P-Value & Model selection \\
\cline { 2 - 4 } & 1156.26 & O & Reject Pooled-OLS \\
\hline \multirow{4}{*}{ Hausman test } & Hausman & P-Value & Model selection \\
\cline { 2 - 4 } & 33.03 & O & Reject RE \\
\cline { 2 - 4 } & Robust Hausman & P-Value & Model selection \\
\cline { 2 - 4 } & 35.204 & O & Reject RE \\
\hline
\end{tabular}


Table 3 shows that both the F Test and LM Test results show that the null hypothesis can be rejected at the significance level of $5 \%$. There are significant individualities and differences among data of provincial administrative regions, and the panel model does not conform to the Pooled-OLS Model. Both the Hausman Test and the Robust Hausman Test show that at the significance level of $5 \%$, the individual effect of data in the provincial administrative region is related to explanatory variables, and the panel model should reject the Random Effect Model and choose the Fixed Effect Model. Therefore, panel model A should use the Fixed Effect Model.

\subsection{Regression Analysis of the Static Panel Model-the Interactive Model}

Now the panel model B which added with interaction terms is regressed using the methods of PooledOLS Model, Fixed Effect Model and Random Effect Model, and all the regression results are based on the cluster-robust standard error. This paper also uses the F Test, LM Test, Hausman Test and Robust Hausman Test to verify the model setting. The regression results of Pooled-OLS Model, FE Model and RE Model are shown in Table 4.

Table-4. Regression results of panel model B (adding interaction terms).

\begin{tabular}{|c|c|c|c|c|c|}
\hline & $(1)$ & $(2)$ & (3) & $(4)$ & $(5)$ \\
\hline lnfdi & Pooled-OLS & FE_Within & FE_LSDV & RE_FGLS & RE_MLE \\
\hline \multirow[t]{2}{*}{ ipe } & 0.0427 & $0.106^{* * *}$ & $0.106^{* * * *}$ & $0.112^{* * * *}$ & $0.110^{* * * * *}$ \\
\hline & $(0.0816)$ & $(0.0342)$ & (0.0353) & $(0.0381)$ & $(0.0242)$ \\
\hline \multirow[t]{2}{*}{ ipl } & -0.00977 & $0.00596^{* * * *}$ & $0.00596^{* *}$ & 0.00345 & 0.0043 \\
\hline & $(0.0110)$ & $(0.0022)$ & $(0.0022)$ & $(0.0025)$ & $(0.0027)$ \\
\hline \multirow[t]{2}{*}{$\operatorname{lnfti}$} & $0.105^{* * * *}$ & 0.0123 & 0.0123 & 0.0223 & 0.0185 \\
\hline & $(0.0371)$ & $(0.0191)$ & $(0.0198)$ & $(0.0163)$ & $(0.0159)$ \\
\hline \multirow[t]{2}{*}{ lnopen } & $0.567^{* * * *}$ & $0.178^{* *}$ & $0.178^{* * *}$ & $0.321^{* * * *}$ & $0.276^{* * * *}$ \\
\hline & $(0.1180)$ & $(0.0671)$ & $(0.0694)$ & $(0.0591)$ & $(0.0498)$ \\
\hline \multirow[t]{2}{*}{$\ln r d$} & 0.0708 & $0.225^{*}$ & $0.225^{*}$ & $0.271^{* * * *}$ & $0.265^{* * * *}$ \\
\hline & $(0.1560)$ & $(0.1240)$ & $(0.1280)$ & $(0.0878)$ & $(0.0561)$ \\
\hline \multirow[t]{2}{*}{$\operatorname{lnfi}$} & 0.0441 & 0.189 & 0.189 & 0.0368 & 0.0766 \\
\hline & $(0.0724)$ & $(0.1140)$ & $(0.1180)$ & $(0.0690)$ & $(0.0519)$ \\
\hline \multirow[t]{2}{*}{ iplfti } & -0.00976 & $-0.0537^{* * *}$ & $-0.0537^{* * *}$ & $-0.0491^{* * * *}$ & $-0.0507^{* * * *}$ \\
\hline & $(0.0298)$ & $(0.0086)$ & $(0.0089)$ & $(0.0095)$ & $(0.0154)$ \\
\hline \multirow[t]{2}{*}{ ipefti } & -0.0274 & -0.0441 & -0.0441 & -0.0435 & $-0.0447^{* * *}$ \\
\hline & $(0.0393)$ & $(0.0313)$ & $(0.0324)$ & $(0.0316)$ & $(0.0203)$ \\
\hline \multirow[t]{2}{*}{ _cons } & $1.745^{*}$ & 0.732 & 0.604 & 0.458 & 0.503 \\
\hline & $(0.9390)$ & $(0.6640)$ & $(0.7360)$ & $(0.5470)$ & (0.3230) \\
\hline$R^{2}$ & 0.879 & 0.804 & 0.967 & & \\
\hline
\end{tabular}

Column (1) in Table 4 shows the results of regression using Pooled-OLS Model. The results show that the regression coefficient of intellectual property legislation level is negative, which is inconsistent with the expectation .The coefficient of intellectual property law enforcement level is postive, which is consistent with the expectation of this paper, indicating that the stronger the enforcement of intellectual property rights is, the more China's FDI growth will be promoted. But neither is significant. The interaction coefficient between the level of intellectual property law enforcement and the level of foreign technology import is negative, indicating that when considering the joint effect of foreign technology import level and intellectual property protection, strengthening intellectual property protection can only restrain FDI inflow. That is because China's economic development still depends on technology introduction and technology imitation. And strong intellectual property protection system will affect technology introduction, thus affecting the level of economic development and intentions of foreign investment. But neither is significant.

Column (2) and column (3) in Table 4 are the results of regression using the Fixed Effect Model, where column (2) uses the Within Estimation method, and column (3) uses the LSDV method. The results show that the regression coefficient of intellectual property legislation level is 0.00596 , and the significance level was $1 \%$ ( Within Estimation method) and 5\%(LSDV method). The coefficient of IPR enforcement level is 0.106 , and the significance level is $1 \%$. The coefficient of intellectual property legislation level and intellectual property law enforcement level is positive and significant, which is in line with the expectation. Compared with regression results of panel model $\mathrm{A}$, panel model $\mathrm{B}$ joining interactive items shows the coefficient of intellectual property legislation level is smaller, while the coefficient of intellectual property law enforcement level is larger, and the significance of both are improved. That means when considering the joint effect of foreign technology import level and intellectual property protection, the degree of legislation and enforcement of intellectual property rights have a more significant positive promoting effect on FDI in China. The 
interaction coefficient between intellectual property law enforcement level and foreign technology import level is negative, so as the intellectual property legislation level, which shows when considering the joint effect of foreign technology import level and intellectual property protection, strengthening intellectual property protection can only restrain FDI inflow, especially the inhibiting effect of strengthening intellectual property protection legislation level is significant at $1 \%$ level. The regression results of other control variables in the model are in line with the expectation, but the regression coefficients of foreign technology introduction and fixed asset investment are not significant

Column (4) and column (5) in Table 4 are the results of regression using Random Effects Model, where column (4) uses the FGLS method, and column (5) uses the MLE method. The results show that the regression coefficient of intellectual property legislation level using FGLS method is 0.00345 , but not significant. The coefficient of IPR enforcement level using FGLS method is 0.112, and the significance level is $1 \%$. The regression coefficient of intellectual property legislation level using MLE method is 0.0043, but not significant, while the regression coefficient of intellectual property law enforcement level using MLE method is 0.110 , and the significance level is $1 \%$. The regression coefficient of intellectual property legislation level and intellectual property law enforcement level is positive, which is consistent with the expectation. However, the coefficient of the legislative level of intellectual property is not significant using the two methods. Compared with the regression results of panel model $\mathrm{A}$, the regression coefficient of intellectual property legislation level becomes smaller and the significance decreases after the interaction term is added in panel model $\mathrm{B}$. While the regression coefficient of intellectual property law enforcement level increases and the significance remains unchanged. It shows that when considering the combined effect of foreign technology import level and intellectual property protection, the positive promotion effect of intellectual property legislation on FDI in China is significantly reduced. The interaction coefficient between intellectual property law enforcement level and foreign technology import level is negative, so as the intellectual property legislation level. It means that when considering the joint effect of foreign technology import level and intellectual property protection, strengthening intellectual property protection can only restrain FDI inflow, especially the inhibiting effect of strengthening intellectual property protection legislation level is significant at $1 \%$ level. The regression results of other control variables in the model are in line with the expectation, but the regression coefficients of foreign technology introduction and fixed asset investment are not significant.

In Table 4 different regression methods are used to obtain different results for panel model B. Therefore, F Test, LM Test, Hausman Test and Robust Hausman Test are used to verify the model setting, as shown in Table 5 .

Table-5. Test of panel model B (adding interaction terms) setting.

\begin{tabular}{l|l|l|l}
\hline \multirow{2}{*}{ F test } & F-value & P-value & Model selection \\
\cline { 2 - 4 } & 37.61 & O & Reject pooled-OLS \\
\hline \multirow{4}{*}{ LM test } & $\boldsymbol{\chi}^{2}$ & P-value & Model selection \\
\cline { 2 - 4 } & 1142.16 & O & Reject pooled-OLS \\
\hline \multirow{4}{*}{ Hausman test } & Hausman & P-value & Model selection \\
\cline { 2 - 4 } & 35.94 & 0 & Reject RE \\
\cline { 2 - 4 } & Robust Hausman & P-value & Model selection \\
\cline { 2 - 4 } & 38.422 & 0 & Reject RE \\
\hline
\end{tabular}

Table 5 shows that both the $\mathrm{F}$ Test and LM Test results mean that the null hypothesis can be rejected at the significance level of $5 \%$. There are significant individualities and differences among data of provincial administrative regions, and the panel model does not conform to the Pooled-OLS model. Both the Hausman Test and the Robust Hausman Test show that at the significance level of $5 \%$, the individual effect of data in the provincial administrative region is related to explanatory variables, and the panel model should reject the Random Effect Model and choose the Fixed Effect Model. Therefore, panel model B should use the Fixed Effect Model for regression.

\subsection{Regression Analysis of Dynamic Panel Model}

The dynamic panel model $\mathrm{C}$ has endogenous problems due to the inclusion of FDI lags, and the OLS estimation method will lead to inconsistent problems, so Difference GMM estimation method or System GMM estimation method should be used. Therefore, Difference GMM estimation method and System GMM estimation method are respectively used in this paper to carry out regression of dynamic panel model C. The test for autocorrelation in first-differenced errors, autocorrelation in second-differenced errors and Sargan test of overidentifying restrictions are also carried out. The regression results of panel model $\mathrm{C}$ are shown in Table 6. 
Table-6. Regression results of dynamic panel model C.

\begin{tabular}{|c|c|c|}
\hline lnfdi & (1) Difference GMM & (2) System GMM \\
\hline \multirow[t]{2}{*}{ L.lnfdi } & $0.756^{\text {***** }}$ & $0.851^{* * * *}$ \\
\hline & $(0.2840)$ & $(0.0487)$ \\
\hline \multirow[t]{2}{*}{ ipl } & $0.0362^{*}$ & 0.0312 \\
\hline & $(0.0188)$ & $(0.0204)$ \\
\hline \multirow[t]{2}{*}{ ipe } & $0.00654^{*}$ & $0.00700^{* * *}$ \\
\hline & $(0.0036)$ & $(0.0033)$ \\
\hline \multirow[t]{2}{*}{$\operatorname{lnfti}$} & -0.0086 & -0.012 \\
\hline & $(0.0136)$ & $(0.0141)$ \\
\hline \multirow[t]{2}{*}{ lnopen } & 0.0355 & 0.0748 \\
\hline & $(0.0439)$ & $(0.0563)$ \\
\hline \multirow[t]{2}{*}{$\ln r d$} & -0.0724 & -0.0527 \\
\hline & $(0.1380)$ & $(0.0571)$ \\
\hline \multirow[t]{2}{*}{$\operatorname{lnfi}$} & 0.156 & 0.0632 \\
\hline & $(0.1720)$ & $(0.0393)$ \\
\hline \multirow[t]{2}{*}{ _cons } & 0.957 & $0.583^{*}$ \\
\hline & $(0.7060)$ & $(0.3330)$ \\
\hline $\operatorname{AR}(1)$ & 0.0737 & 0.0054 \\
\hline $\operatorname{AR}(2)$ & 0.9808 & 0.9755 \\
\hline sargan & 0.0446 & 0.4264 \\
\hline
\end{tabular}

After the FDI lag was added to the model in Table 6 the regression results using the Difference GMM method in column (1) show that the first-order lag value of the explained variable was significant at the $1 \%$ level. The regression coefficient of intellectual property protection legislation level and intellectual property protection law enforcement level is positive, which is consistent with the expectation of this paper and is significant at the level of $10 \%$.The regression coefficients of other control variables are not significant, and the regression coefficients of foreign technology introduction level and $\mathrm{R} \& \mathrm{D}$ technology development level are negative, which is inconsistent with the expectation of this paper. The results of the tests show that there is autocorrelation in first-differenced errors, but the significance is only $10 \%$, and there is no autocorrelation in second -differenced errors. The Sargan Test results show that the null hypothesis can be rejected at the significance level of $5 \%$, that is, the model does not apply to the Difference GMM estimation method.

Column (2) of Table 6 shows regression results using the System GMM method, which is the first-order lag value of the explained variable is significant at the $1 \%$ level. The regression coefficient of intellectual property protection legislation level and intellectual property protection enforcement level is positive, which is consistent with the expectation of this paper. The regression coefficient of intellectual property protection legislation level is not significant, and the enforcement level of intellectual property protection is significant at the level of $5 \%$.The regression coefficients of other control variables are not significant, and the regression coefficients of foreign technology introduction level and R\&D technology development level are negative, which is inconsistent with the expectation of this paper. The results of the tests show that there is autocorrelation in first-differenced errors, and the significance is only $1 \%$, while there is no autocorrelation in second -differenced errors. The results of Sargan Test show that the null hypothesis can be accepted at the significance level of $5 \%$, that is, the model is applicable to the System GMM estimation method.

The Difference GMM estimation method has some problems. For example, there are problems about weak IV and errors from small sample, and the regression coefficient of time-invariant variables can not be estimated. Another problems like underestimating the regression coefficient of explanatory variables in lag period. Accordingly, the System GMM estimation method is more effective. This method can estimate the regression coefficient of time-invariant variables, reduce small sample errors, and deal with endogeneity problems effectively. In addition, the sample characteristics in this paper belong to the case of large $\mathrm{N}$ and small T, so the System GMM estimation method is more suitable for the dynamic panel model. That is to say, China's FDI inflows present a significant dynamic continuity. But compared with static panels fixed effects model, the regression coefficients of intellectual property protection legislation level and intellectual property protection enforcement level are still positive, and the enforcement level of IPR protection is above the $5 \%$ level, but the level of intellectual property rights protection legislation is no longer significant.

\section{Conclusions and Implications}

This paper constructs static panel and dynamic panel models to verify the impact of intellectual property protection legislation level and intellectual property protection enforcement level on FDI inflow. Moreover, a static panel model is constructed to introduce the interaction between the level of intellectual property protection legislation, the level of intellectual property protection law enforcement and the level of foreign technology introduction. For the static panel model, this paper used the Pooled-OLS, Fixed Effect and 
Random Effect Model respectively for regression. And F Test, LM Test, Hausman Test and Robust Hausman Test are used to test the model setting, and finally the Fixed Effect Model is selected. For the dynamic panel model, the Difference GMM estimation method and the System GMM estimation method are used for regression respectively. And by test for autocorrelation in differenced errors and Sargan test of overidentifying restrictions, the System GMM estimation method is finally selected. After the regression analysis, the following conclusions are drawn.

Intellectual property protection legislation level and intellectual property protection enforcement level have significant positive impact on FDI inflow in China. Which means the greater the degree of legislation and enforcement of intellectual property rights protection, the greater the increase of FDI inflow in China. However, if the combined effect of foreign technology import level and intellectual property protection level is taken into account, the regions with a higher level of foreign technology import are those in urgent need of foreign advanced technology introduction. For these regions, strengthening intellectual property protection will inhibit FDI inflow, especially the inhibiting effect of strengthening intellectual property protection legislation level is more obvious. In addition, China's FDI inflow shows a significant dynamic continuity. The regression results of the dynamic panel model show that the legislation level of intellectual property protection and the law enforcement level of intellectual property protection still have a positive impact on China's FDI inflow, but the positive impact of the legislation level of intellectual property protection is no longer significant.

According to the research conclusion of this paper, first of all, strengthening the legislative and law enforcement intensity of intellectual property protection has a certain promoting effect on attracting foreign investment and increasing FDI inflow. However, the appropriate level of legislation and enforcement of intellectual property protection should be determined according to the characteristics of the specific administrative region. That is to say, technology learning, imitation and innovation is an important way to promote technological renewal and economic development for the provincial administrative regions that are in urgent need of introducing advanced foreign technologies. Therefore, the weak IPR protection system is more conducive to the inflow of FDI in these regions, especially in the aspect of IPR protection legislation.

\section{References}

Carsten, F., Braga, P., \& Carlos, A. (2001). How stronger protection of intellectual property rights affects intellectual trade flows. World Bank Working Paper, No. 2051.

Ginarte, J. C., \& Park, W. G. (1997). Determinants of patent rights: A cross-national study. Research Policy, 26(3), $283-301$. Available at: https://doi.org/10.1016/s0048-7333(97)00022-x.

Han, Y. X., \& Li, H. Z. (2005). Quantitative analysis for intellectual property protection level of China. Studies in Science of Science, 23(3), 377-382.

Li, L. M., \& Chen, M. Y. (2017). Patent-intensive industry, patent system and economic growth. China Soft Science, 4, 152168.

Maskus, K. E. (1998). The international regulation of intellectual property. Weltwirtschaftliches Archiv, 134(2), 186-208.

Maskus, K. E., \& Penubarti, M. (1995). How trade-related are intellectual property rights? Journal of International Economics, 39(3-4), 227-248.

Nordhaus, W. D. (1969). Invention, growth and welfare: A theoretical treatment of technological change. Cambridge: M.I.T. Press.

Shi, Y. P., \& Gu, Q. L. (2013). Intellectual property protection, heterogeneous enterprises and innovation: Evidence from Chinese manufacturing. Financial Research, 8, 136-149.

Xu, C. M., \& Shan, X. G. (2008). Constructing of the index system and verification for the intensity of intellectual property protection in China. Studies in Science of Science, 26(4), 715-723.

Yang, Q., \& Ying, H. (2006). Intellectual property right protection and FDI strategies of MNE. Economic Research Journal, 4, 28-34.

Yu, C. L., \& Wang, R. F. (2009). Intellectual property rights protection, host country characteristics and FDI: An empirical study across countries. World Economy Study, 10, 59-67. 